\title{
De elecciones y chanchullos: la contienda electoral por la gubernatura de Oaxaca en 1924
}

\author{
Daisy Ramírez \\ Universidad Autónoma Metropolitana-Iztapalapa \\ dredaii.09@gmail.com
}

\section{Resumen}

El artículo analiza el proceso electoral para gobernador en el estado de Oaxaca durante el mes de agosto de 1924, en el que tuvo una participación importante José Vasconcelos, destacado intelectual oaxaqueño, que recién había renunciado a la Secretaría de Educación, que él mismo había contribuido a crear. Se analiza a los distintos candidatos, los partidos que los postularon, así como la forma en que se realizó el proceso electoral y las acciones posteriores llevadas a cabo, sobre todo, por los seguidores de Vasconcelos, quienes, de cualquier forma, no pudieron modificar el resultado que declaró como ganador al general Onofre Jiménez.

Palabras clave: José

Vasconcelos, Oaxaca, elecciones, gobernador

\section{Abstract}

The article analices the electoral process which took place in Oaxaca in August 1924, for the governmental office of the state, in which José Vasconcelos, a prominent and politically influential intellectual had a significant participation. This works deals with the different candidates, the political parties which supported them, and the main characteristics of the electoral process as a whole, afterwards the official candidate Onofre Jiménez was declared the winner.

Keywords: José Vasconcelos, Oaxaca, elections, governor 


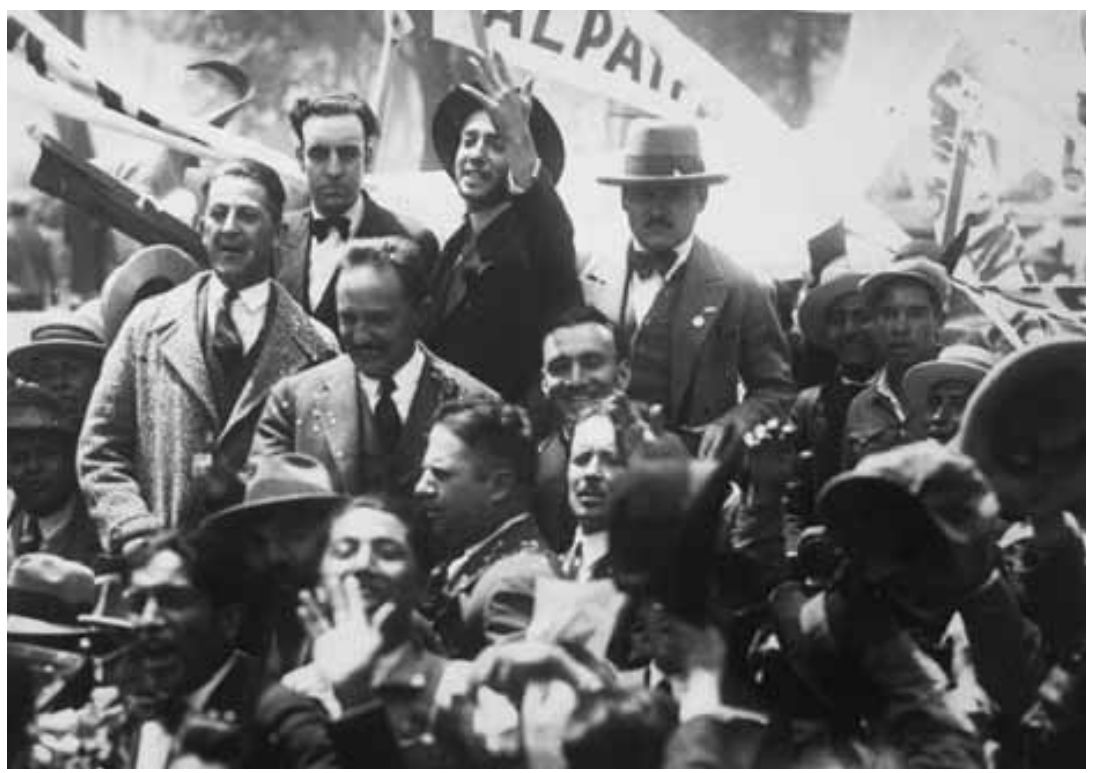

Vasconcelos en un mítin. Archivo General de la Nación, México, Fondo Díaz Delgado y García, caja 25/26.

"El señor licenciado Vasconcelos declaró a la prensa lo siguiente: 'la medida que hemos tomado contra los atropellos, es obtener el triunfo: a cada chanchullo responderemos con una victoria $[\ldots]$ Tenemos segura la victoria, no sólo en la elección de gobernador, sino en la de diputados $[\ldots]$ '

El general Jiménez dijo: 'Puede usted decir al pueblo de Oaxaca, que estoy satisfecho del resultado de las elecciones [...] cuanto que se llevaron a cabo dentro de la ley y del más profundo respeto al sufragio del pueblo que es sagrado'."

"Gran entusiasmo hubo en las elecciones en Oaxaca" en Excélsior, 8 de agosto de 1924. 


\section{Introducción}

El objetivo de este ensayo consiste en analizar las elecciones para gobernador en el estado de Oaxaca, proceso conocido a partir de las memorias de uno de los candidatos participantes: El Desastre. Tercera parte de Ulises Criollo ${ }^{1}$ donde el autor, José Vasconcelos, realiza un relato de su participación y campaña electoral en el proceso. Sin embargo, en la historiografía regional son escasas las menciones de este episodio y los trabajos especializados. Por ejemplo, en 1956, Jorge Tamayo refiere lo acontecido en la elección de 1924 sosteniendo que: "[...] Vasconcelos arrastró simpatizantes, pero su notorio anticallismo hizo imposible su llegada al gobierno; se le dio el triunfo al gral. [Onofre] Jiménez y Vasconcelos salió del país, olvidando a sus partidarios comprometidos y al estado". ${ }^{2}$ Luis Barrón, en su trabajo titulado "Un civil en la busca del poder: la carrera política de José Vasconcelos 1911-1924”, detalló la participación política y campaña de Vasconcelos en Oaxaca, episodio decisivo en la vida del intelectual; reconstruyendo este acontecimiento, y a partir de fuentes hemerográficas de la época como El Universal.

Para elaborar este ensayo se recurrió a la documentación de la Dirección de Investigaciones Políticas y Sociales (DIPys) ${ }^{3}$ del Archivo General de la Nación (AGN). Del expediente analizado se utilizaron recortes de periódicos nacionales y estatales, los cuales se citan a lo largo del texto, así como informes realizados por agentes enviados para investigar el tema de la elección de gobernador en 1924. La formalidad de la documentación y su valor son innegables por haber sido meticulosamente seleccionados por esos agentes.

${ }^{1}$ La edición consultada para este artículo es la de Fondo de Cultura Económica, 1989.

2 Tamayo, Oaxaca en el siglo xx, p. 65.

${ }^{3}$ La DIPyS cuenta con documentación fechada desde 1920 hasta 1952, información confidencial y de seguridad nacional que consiste en una amplia gama de oficios, recortes de periódicos, cartas, telegramas, informes, fotografias, revistas, etcétera. Mucho de este material fue recopilado por los agentes de investigación encomendados para dicha tarea. 
A partir de lo anterior se ha dividido el presente ensayo en apartados. En el primero se presenta una semblanza de Oaxaca durante el periodo 1920-1924. A partir de la década de 1920 en la política nacional, una de las tareas de la llamada hegemonía sonorense fue la búsqueda de la estabilización política y social en el país. Oaxaca se caracterizó, durante los años revolucionarios, por ser una fuerza disidente regional, por lo que uno de los objetivos fue enmarcar a la entidad a las disposiciones del centro. Con la elección del general Manuel García Vigil inició en el estado esta tarea; no obstante, su periodo no culminó satisfactoriamente porque en 1923 el gobernador apoyó la revuelta delahuertista en la entidad, la cual reflejó una crisis política estatal y nuevamente un foco rojo de inestabilidad en el país derivando en la elección - que es tema de este ensayo.

En el segundo apartado se explica el proceso de elección para gobernador en Oaxaca. En el primer punto se desarrollan las disposiciones legales para llevar a cabo la elección, a partir de la constitución local y de la ley electoral de la entidad. En el segundo se caracterizan los partidos políticos y los candidatos independientes participantes. En el tercero se aborda lo relacionado con la trayectoria de los candidatos Rubén Morales, Onofre Jiménez y José Vasconcelos. El cuarto punto trata de la información existente acerca de la forma en que se llevaron a cabo las campañas electorales de cada candidato.

En el tercer apartado se desarrolla lo acontecido en las elecciones del 3 de agosto de 1924; los resultados, las especulaciones, los inconvenientes, los chanchullos, etcétera, resaltando, al final, las acciones postelectorales derivadas del conflicto en Oaxaca. Finalmente, se presentan las conclusiones de esta investigación.

\section{Semblanza. Oaxaca 1920-1924}

Durante la década de 1920 una de las tareas emprendidas por la facción triunfadora, es decir, los sonorenses, fue reunir a todas las fuerzas participantes de la Revolución y enmarcarlas en el proceso de centralización política. En relación con lo anterior, Tobler considera que el periodo transcurrió "[...] bajo el signo de la 
creciente estabilización política y social de la hegemonía de los políticos sonorenses, por lo que se puede hablar de un periodo de hegemonía sonorense a nivel nacional". ${ }^{4}$ Este patrón demostró que el poder descansaba en los caudillos nacionales, es decir, Obregón y Calles; en el caso de los estados, en los caudillos y caciques regionales; además, se demostró que el peso de los partidos políticos existentes era menor frente al poder ejecutivo representado por el presidente. Tobler concluye que "esto se debió principalmente al hecho de que los partidos políticos no contaban con una verdadera base social ni con las estructuras institucionales desarrolladas, sino más bien representaba clubes electorales y parlamentarios formados ad hoc".

En el caso del estado de Oaxaca, como menciona Margarita Dalton: "Para comprender la historia [de Oaxaca] es indispensable acercarse a su geografía, su configuración orográfica, sus climas, bosques, flora, fauna y a los seres humanos que lo habitan". ${ }^{6}$ Una de las peculiaridades de la entidad es su territorio accidentado, es decir, la presencia de un 60\% de montañas, lo cual puede hacer pensar que se encuentra aislado del centro y de otros estados. No obstante, Paul H. Garner menciona que en Oaxaca se llevaron a cabo diferentes políticas económicas venidas del centro, a pesar de la paradoja de que el esfuerzo realizado sólo tuvo beneficios para los empresarios. ${ }^{7}$

Si bien la geografía ha sido un factor clave para entender el liderazgo de caudillos en Oaxaca, se tiene que considerar que la participación de los oaxaqueños en la vida política nacional, durante la segunda mitad del siglo XIX y principios del XX, para servir a los

${ }^{4}$ Tobler, La Revolución mexicana, p. 419.

${ }^{5}$ Tobler, La Revolución mexicana, p. 425.

${ }^{6} \mathrm{El}$ estado de Oaxaca se localiza en la región sur del país, limitando al norte por los estados de Puebla y Veracruz; al este por el de Chiapas; al oeste por el de Guerrero y al sur por el Océano Pacífico. Su territorio abarca 95, $364 \mathrm{~km}^{2}$ el quinto lugar en extensión territorial del país. Convencionalmente, la división más recurrida para comprender la entidad es la que consiste en ocho regiones: Istmo, Papaloapan, La Cañada, Sierra Norte, Valles Centrales, Sierra Sur, La Mixteca y La Costa. Véase Dalton, Breve historia, pp. 17-19. ${ }^{7}$ Garner, La revolución, p. 10. 
hombres fuertes del país: Benito Juárez y Porfirio Díaz, ${ }^{8}$ es un factor relevante para entender las relaciones entre el centro y la periferia. Sin embargo, la Revolución mexicana originó una serie de cambios con respecto de la hegemonía que tenían los oaxaqueños en la vida política, tal como menciona Sánchez Silva:

La revolución mexicana es de suma importancia para los oaxaqueños. No tanto por su participación como dirigentes, sino porque marcó el desplazamiento de centro de decisiones de los sureños en favor de fracciones norteñas, más ligadas al nuevo desarrollo de las relaciones de corte capitalista. ${ }^{9}$

Este desplazamiento originó en el estado la búsqueda de designar nuevos líderes que entablaran una relación estrecha con el Ejecutivo como pasaba en tiempos anteriores, lo cual fue un intento fallido. Entre 1915 a 1920, Oaxaca se distinguió por una disidencia particular en comparación con otros estados del país, lo que produjo una agitación interna designada por la historiografía como el "movimiento de la soberanía"; ${ }^{10}$ que se caracterizó por la protección de la soberanía constitucional del estado dentro de la federación, amenazada por la

${ }^{8} \mathrm{Al}$ respecto, Chassen considera: "La relación cercana entre el presidente y los políticos que eran sus paisanos surge como un factor central al analizar la política nacional, así como la local. Los oaxaqueños apoyaban y participaban en la autoridad, cada vez mayor, de Díaz en el centro, pero fuera de la ciudad de Oaxaca el regionalismo y localismo todavía eran endémicos, dada la extrema fragmentación política, así como los factores geográficos y étnicos". Chassen-López, Oaxaca p. 456.

${ }^{9}$ Sánchez Silva, Crisis política, p. 15.

${ }^{10}$ Para realizar una revisión sobre el periodo denominado como Movimiento de la Soberanía, véanse los trabajos de Ruiz Cervantes, La Revolución en Oaxaca: el movimiento de la soberanía, 1915-1920 y Garner, La Revolución en la provincia. Soberanía estatal y caudillismo serrano en Oaxaca, 1910-1920 
estrategia de Carranza de impulsar la centralización política. ${ }^{11} \mathrm{La}$ importancia de los caudillos serranos, como menciona Garner, fue fundamental en la génesis del "movimiento de la soberanía", puesto que las movilizaciones de las milicias serranas fueron los elementos clave en la reacción popular de Oaxaca ante el carrancismo. ${ }^{12}$

El periodo de 1920 marca en la entidad la búsqueda de la estabilización política por medio de un candidato que comulgara con el nuevo grupo en el poder. El gobernador provisional del estado, Jesús Acevedo, se encargó de convocar a elecciones para renovar el gobierno.

En este proceso electoral participaron el general Manuel García Vigil respaldado por el gobierno federal y el Partido Liberal Constitucionalista (PLC); seguido por el abogado Manuel Palacios y Silva que representaba a la élite regional, es decir a los serranos. Sin embargo, el gobernador Acevedo no concordaba con apoyar a García Vigil, por lo que este último tuvo que apelar al presidente Adolfo de la Huerta para que, a través de la Secretaría de Gobernación, se relevara a Acevedo por un colaborador más cercano, Carlos Bravo. ${ }^{13}$ A pesar de esta maniobra, las elecciones favorecieron a García Vigil, obteniendo "88,855 votos contra 44,087 de Palacios y Silva": ${ }^{14}$ en diciembre de 1920, García Vigil juraba como gobernador de Oaxaca.

El gobierno de García Vigil contó con el apoyo inicial del presidente de la República así como del congreso local y la legitimidad de haber llegado al poder por la vía electoral. Como menciona Martínez "si en el plano federal Obregón establecía nuevos estilos para hacer política, García Vigil hacía lo mismo en el plano regional". ${ }^{15}$ No obstante, los levantamientos internos en la entidad y la disputa del poder se hicieron constantes a lo largo de su mandato.

${ }^{11}$ Garner, La revolución en la provincia, p. 18.

${ }^{12}$ Garner, La revolución en la provincia, pp. 134-135.

${ }^{13}$ Martínez Vázquez, "Capítulo 5. El régimen de García Vigil", pp. 391-392.

${ }^{14}$ Martínez Vázquez, "Capítulo 5. El régimen de García Vigil”, p. 392.

${ }^{15}$ Martínez Vázquez, "Capítulo 5. El régimen de García Vigil”, p. 397. 
En relación con la obra pública, el gobernador en turno inició un proceso de reforma agraria, así como una mediación profunda con los campesinos, aunque en el estado no se notó un movimiento agrarista organizado, como se produjo en otros estados. En el ámbito del trabajo obrero, los movimientos más representativos del periodo fueron los de la Compañía Minera de Nativitas y Anexas, la de la fábrica de hilados Vista Hermosa, la Cervecera La Zapoteca, el movimiento ferrocarrilero y las protestas en la zona bananera en Tuxtepec. ${ }^{16}$ Los nexos entre los trabajadores y el gobierno estaban ligados con la Confederación de Sindicatos Obreros y -de acuerdo con la época- con la Confederación Regional Obrera Mexicana (CROM).

La relación de las clases medias con el gobierno oaxaqueño consistió en poner en marcha el proyecto de educación gratuita con los apoyos brindados desde el centro a partir de 1921. Se ratificó el subsidio para el Instituto de Ciencias y Artes, así como en los niveles básicos de educación, donde las escuelas empezaban a emerger de manera considerable.

La relación más conflictiva en el periodo de García Vigil fue con las clases económicas dominantes, por la política administrativa de implantar nuevos impuestos y llevar a cabo la recaudación de las contribuciones.

En el ámbito político, a mitad de su gobierno, se renovó la Constitución local con el fin de hacerla concordar con la Constitución federal de 1917, por lo que el 15 de abril de 1922 fue promulgada. ${ }^{17}$ Uno de los principales objetivos de la Constitución estatal fue restablecer las bases para el orden político interno; no sólo ser una copia de la Carta Magna, sino tener sus propias particularidades acorde con la realidad oaxaqueña. No obstante, en ese mismo año, el estado se vio envuelto en disputas electorales durante los comicios para diputados

${ }^{16}$ Martínez Vázquez, "Capítulo 5. El régimen de García Vigil”, p. 398.

${ }^{17}$ Ruiz, La institucionalización de la Revolución (1920-1940), p. 208. 
federales. Los candidatos del Partido Liberal Constitucionalista (PLC), apoyados por el gobernador, disputaron los votos con el Partido Nacional Cooperatista (PNC) y el Partido Laborista Mexicano (PLM) lo que ocasionó "el paulatino distanciamiento entre el gobernante oaxaqueño y uno de los miembros de la triada sonorense, Plutarco Elías Calles". ${ }^{18}$

La sucesión presidencial de 1924 derivó una crisis en la hegemonía sonorense que alteró la vida política nacional y de los estados. Si bien Obregón favoreció la candidatura de Plutarco Elías Calles, otros integrantes del grupo de poder vieron desplazados sus intereses de poder participar en la vida política nacional, entre ellos, Adolfo de la Huerta, colaborador durante el gobierno de Obregón en la Secretaría de Hacienda, que buscaba ocupar la Presidencia de la República, pero al no ser elegido candidato designado desde el centro, se convirtió en el líder de la rebelión en 1923. Las consignas de este levantamiento destacaban que Obregón había traicionado los principios de la Revolución y del sufragio al apoyar a Calles en la sucesión presidencial, además se le relacionó con la muerte de Francisco Villa.

En el ámbito estatal, este rompimiento originó que el 13 de diciembre de 1923 el jefe de operaciones militares de Oaxaca, Fortunato Maycotte, y el propio García Vigil, desconocieran los poderes de la Unión lanzando un plan revolucionario. Uno de los motivos que orilló a García Vigil para integrarse a la rebelión delahuertista fue el atentado que había sufrido el 15 de febrero 1923 y que le obligó a separarse del cargo. Se designó como gobernador interino al licenciado Flavio Pérez Gasga ${ }^{19}$ hasta septiembre de 1923, momento en el que García Vigil se reintegró al cargo. En cuanto al atentado, quedó sin aclarar, sólo se tenía la sospecha que el autor intelectual era el secretario de Gobernación, es decir, Plutarco Elías Calles. ${ }^{20}$

${ }^{18}$ Ruiz Cervantes, "La institucionalización de la Revolución (1920-1940)" p. 209.

${ }^{19}$ Martínez, "Capítulo 5. El régimen de García Vigil”, p. 430.

${ }^{20}$ Martínez Vázquez, "Capítulo 5. El régimen de García Vigil”, p. 443. 
A inicios de 1924, los serranos tomaron la ciudad de Oaxaca. La milicia local se organizó en los municipios y el grupo serrano, liderado por el general Isaac M. Ibarra, buscó desmantelar las fuerzas rebeldes que empezaron a declinar. Casi para terminar marzo de 1924, García Vigil evacuó la ciudad de Oaxaca, aunque fue rodeado por las fuerzas obregonistas para su inmediata captura. A pesar de buscar un acercamiento con Obregón, García Vigil fue fusilado el 19 de abril de 1924.

La participación de los serranos fue decisiva para tomar las riendas del estado, designándose al general Isaac M. Ibarra como gobernador provisional el 24 de abril de 1924, cuya tarea principal fue convocar nuevas elecciones. La rebelión y la muerte de García Vigil, en 1924, ocasionaron desestabilización política, así como un reacomodo de las fuerzas regionales internas, lo que derivó que - de nuevo- el grupo serrano se posicionara en la política estatal.

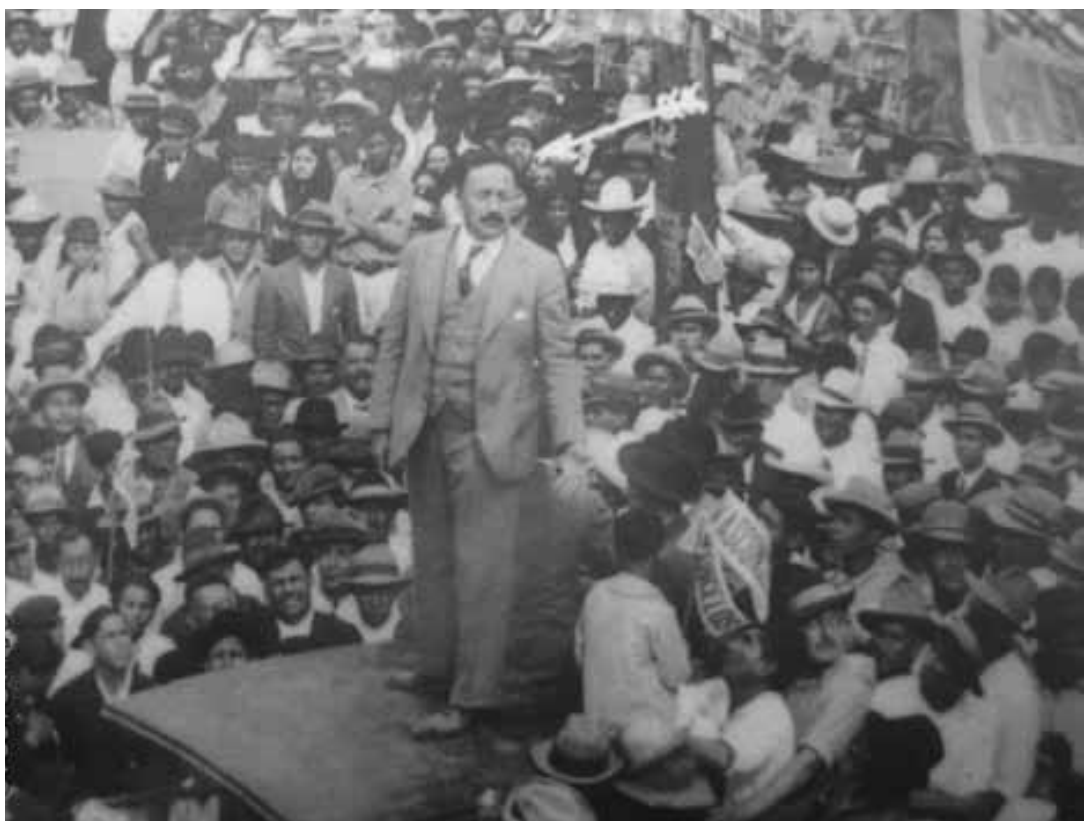

Vasconcelos durante su campaña para gobernador. Archivo General de la Nación, México, Fondo Díaz Delgado y García, caja 22/16. 


\section{Los preparativos de la elección de 1924}

\section{Disposiciones legales en torno a la elección de gobernador}

Tras la rebelión delahuertista en Oaxaca y el fusilamiento de García Vigil, se designó como gobernador provisional al general Isaac M. Ibarra, quien tuvo la tarea de renovar el Poder Ejecutivo del estado y reordenar la vida política en la entidad.

Para entender el proceso de elección a gobernador de 1924 en Oaxaca es necesario remitirse a los requisitos establecidos en la Constitución Política del Estado Libre y Soberano del Estado de Oaxaca, promulgada durante la gestión de García Vigil, en la cual se establecen reglas para efectuar las elecciones del Ejecutivo estatal. En el artículo 67 del texto constitucional se menciona: "la elección de Gobernador será directa. La legislatura del Estado hará la computación de los votos y su calificación y se declarará electo al ciudadano que haya obtenido la mayoría absoluta de los votos emitidos, haciéndolo saber al pueblo, por medio de un decreto". ${ }^{21}$ Un aspecto por considerar en la elección es la fecha que estipula la Ley para las elecciones de los poderes Legislativo y Ejecutivo del Estado, promulgada el 13 de julio de 1922;22 el Capítulo I, artículo 1 menciona que: "las elecciones ordinarias para la renovación de los poderes Legislativo y Ejecutivo del estado se celebrará en los términos que previene la constitución del mismo, el primer domingo del mes de agosto de los años terminados en cero o cifra par", ${ }^{23}$ por consiguiente tanto la elección para gobernador como la de diputados locales se efectuaron el domingo 3 de agosto de 1924.

21 "Constitución Política del Estado libre y Soberano de Oaxaca. 4 de abril de 1922" en Villegas Moreno, La estabilidad política, p. 748.

${ }^{22}$ La Ley para las elecciones de los poderes Legislativo y Ejecutivo del Estado. 13 de julio de 1922, fue publicada por primera vez el 15 de julio de 1922, en el Periódico Oficial del Estado, t. III, núm. 25.

23 "Ley para las elecciones de los poderes Legislativo y Ejecutivo del Estado. 13 de julio de 1922” en Martínez Sánchez, Leyes, decretos, 2003, p. 108. 
Otra de las disposiciones legales en torno a las elecciones está en el artículo 98 de la Ley para las elecciones, donde se mencionan algunas disposiciones para la intervención de los partidos políticos:

I. Estar organizados en todo el estado [...]

II. Tener en la capital del estado una mesa o Junta Directiva conforme a los estatutos del partido.

III. Tener un programa político de gobierno, aprobado en asamblea general $[\ldots]$

IV. Tener registrado en la Secretaría del Despacho, el acta constitutiva del partido debidamente protocolizada [...]

V. Tener una denominación que no indique credo religioso alguno.

VI. Registrar sus candidaturas dentro del término que fija el artículo $18 .^{24}$

Uno de los aspectos de mayor controversia en esa elección de gobernador fue el incumplimiento de los requisitos, estipulados en el artículo 68 del texto constitucional, por dos de los candidatos:

I. Ser mexicano por nacimiento, en el ejercicio de sus derechos y nativo del estado, o vecino durante un periodo no menor de cinco años inmediatamente anteriores de la elección.

II. Tener treinta y cinco años cumplidos el día de la elección.

III. No ser presidente de la República, secretario de Estado, secretario general del Despacho, magistrado del tribunal superior, procurador general o tesorero general del Estado a menos que se separe por daños [sic] antes de la elección.

IV. No ser funcionario judicial de la Federación con jurisdicción.

V. No haber intervenido directa ni indirectamente en ninguna asonada, motín o cuartelazo.

24 "Ley para las elecciones de los poderes Legislativo y Ejecutivo del Estado. 13 de julio de 1922" en Martínez Sánchez, Leyes, decretos, p. 78. 
VI. No tener parentesco de consanguinidad en los cuatro primeros grados, ni de afinidad de los dos primeros con el gobernador saliente.

VII. Separarse del servicio con dos años de anticipación el día de la elección, si se trata de miembros del Ejército Nacional.

VIII. Tener un modo honesto de vivir. ${ }^{25}$

En lo que respecta a las candidaturas independientes, la Ley para las elecciones menciona, en el artículo 99, que los candidatos independientes podían intervenir en los asuntos electorales cumpliendo los siguientes requisitos:

I. Que sean postulados por un número de ciudadanos igual, cuando menos, al de los miembros de un partido político reconocido, que tenga menor número;

II. Que publiquen un programa político en el distrito o distritos electorales en que debe efectuarse la elección, cuando menos dos veces antes de ésta. En los municipios en que no se haya hecho la publicación, no se concederá intervención en los actos electorales a los candidatos o sus representantes;

III. Que la postulación sea hecha tres meses antes del día de las elecciones, cuando menos;

IV. Que dentro de los ocho días siguientes a la postulación se registre el acta de ésta en el Ayuntamiento de la cabecera del distrito electoral, si se trata de la elección de diputados, o en la Secretaría General del Despacho, si de la de gobernador;

V. Que se registre la candidatura en el término que fija el artículo $18{ }^{26}$

Pese a lo establecido en la ley electoral, poner en práctica estas disposiciones no fue una tarea fácil porque los partidos políticos se

25 "Constitución Política del Estado libre y Soberano de Oaxaca. 4 de abril de 1922" en Villegas Moreno, La estabilidad política, p. 748.

26 "Ley para las elecciones de los poderes Legislativo y Ejecutivo del Estado. 13 de julio de 1922” en Martínez Sánchez, Leyes, decretos, p. 109. 
constituían durante el proceso electoral, sin una verdadera base social ni estructuras institucionales, representados por la figura de caudillos nacionales y regionales.

En Oaxaca - como se demuestra en el siguiente apartado-, los partidos que se encontraban en el escenario político desde 1920 y que habían participado en las elecciones de ese año y las intermedias de 1922, fueron el Partido Liberal Constitucionalista (PLC), el Partido Nacional Cooperatista (PNC) y el Partido Laborista Mexicano (PLM).

\section{Los partidos políticos y la candidatura independiente}

La información sobre los partidos políticos que participaron en la jornada electoral de agosto de 1924, nos las brinda el "Informe del Agente de Primera núm. 8...", que menciona cuáles eran los partidos políticos, su origen y a quién respaldaban en la elección:

[El Partido] Liberal Independiente, que postuló al coronel Rubén Morales. Está fundado recientemente y casi sin organización. Tuvo su origen del Partido Revolucionario Nacionalista de México. Lo integran pequeños propietarios de diversos pueblos del estado. El señor Rodolfo Villareal dice ser quien lo dirige.

[El] Partido Demócrata Revolucionario. Postuló al General Onofre Jiménez. Esta agrupación creada por el señor general Isaac Ibarra, actual gobernador del Estado, para fines de su propaganda cuando era candidato a la gubernatura. Está ramificado en todo el estado y sus trabajos de propaganda datan desde principio del año próximo pasado.

[El] Partido Sierra Juárez, que postuló asimismo al General Onofre Jiménez. Sus elementos sólo radican en la Sierra de Ixtlán. Los partidos Agrarista y Laborista Mexicano, son los únicos partidos que en realidad existen en el Estado. Postularon también al General Onofre Jiménez; tienen pocos elementos y dejan mucho que 
desear por lo que respecta a la coherencia y disciplina que deben de tener los partidos bien organizados.

El grupo de Independientes [candidatura indepen diente] que sostienen la candidatura del licenciado Vasconcelos, está constituido por los elementos más intelectuales del Estado que militaron en el Partido Liberal Constitucionalista. En su mayoría, casi en su totalidad secundaron el movimiento rebelde encabezado por García Vigil o simpatizaban con él. Su organización ha sido a base de prestigio personal de sus componentes y muy especialmente del Lic. José Vasconcelos. ${ }^{27}$

Conforme con lo anterior, se puede pensar que los partidos activos, hasta ese momento, eran: Partido Liberal Independiente, Partido Demócrata Revolucionario, Partido Sierra Juárez, Partido Agrarista Oaxaqueño, Partido Laborista Oaxaqueño y Partido Liberal Constitucionalista; aunque este último fuera filial de muchos vasconcelistas que se consideraba una candidatura independiente. El "Informe del Agente de Primera núm. 8...", da una descripción sobre la fuerza aparente y efectiva que se muestra en la siguiente cita:

El Partido Liberal Independiente que según declaraciones del señor Rodolfo Villarreal está respaldado por treinta y cinco mil campesinos organizado en sesenta y cinto Ligas de Resistencia.

El Partido Agrarista no representa una fuerza real en el estado. Creado artificialmente por agitadores que sólo persiguen escalar los puestos públicos. El Partido Laborista, teniendo en cuenta la incipiente industria ya que no es posible la instauración y funcionamiento de grandes

${ }^{27}$ AGN, "Informe del Agente de Primera núm. 8 sobre las elecciones de poderes locales verificadas de Oaxaca", DIPys, c. 174, exp. 2, ff. 65-66. 
sindicatos porque falta lo principal para formarlos: el obrero.

El Demócrata Revolucionario, creado por el general Ibarra para su propaganda a la gubernatura y puesto al servicio del general Onofre Jiménez. Pertenecen a esta agrupación, todas las autoridades políticas del estado.

[El Partido] Sierra Juárez constituido exclusivamente con elementos serranos, de un grupo de los cuales es Jefe el actual Gobernador, cuenta, como es natural, con el apoyo oficial. No controla la opinión de la Sierra de Ixtlán, pues una buena parte de los pueblos serranos, apoyan a uno de los jefes de la región: el Gral. Otilio Jiménez Madrigal.

El grupo que postuló al señor Vasconcelos también tiene una fuerza considerable, pues por la falta de rápidas vías de comunicación no pudieron darse cuenta en el Estado de la situación en la que quedaron los líderes del Partido Peleceano y en la mayoría de esos lugares apartados se consideran aún favorecidos por el gobierno Federal. Los García Vigilistas desarrollaron sus actividades con el mayor esfuerzo, tratando de salir de la crítica situación en la que la fracasada revolución los había colocado. Tiene mucho el partido en las clases media y acomodada y también aunque menos que el General Jiménez, en la clase humilde. ${ }^{28}$

El informe menciona algunas de las características, tendencias políticas y las diferencias entre los partidos que contendieron señalando lo siguiente:

Son tan heterogéneos los partidos que postularon al señor

Onofre Jiménez, que no es posible definir sus tendencias

${ }^{28}$ AGN, DIPys, c. 174, exp. 2, ff. 66-68. 
en conjunto. El Demócrata Revolucionario y el Sierra Juárez tratan de perpetuar en el poder a sus hombres.

Por lo que respecta al Agrario y Laborista son bien conocidas sus tendencias en todo el país: llevan al extremo todas las teorías y métodos de disolución social e imperar por la fuerza o el terror, no por la justicia de los procedimientos ni por el convencimiento de los espíritus.

El Partido Liberal Independiente, según declaraciones de sus líderes no es un partido de clase. Sus tendencias están cumplidas, ya que sólo trataron de llevar al poder a aquellos candidatos que juzgaron más capacitados para laborar por el engrandecimiento y prosperidad del Estado.

Este partido se concretó exclusivamente a la propaganda en favor del señor Calles para la presidencia de la República, y del Coronel Rubén Morales para la gubernatura.

El grupo Vasconcelista representa una tendencia moderada. Sus líderes declaran que desean la cooperación de todos los hombres de buena voluntad que quieran laborar por el bienestar del Estado, sin que los guíen los prejuicios ni personalismos; que en caso de obtener el triunfo los puestos públicos no serán canonjías para crear holgazanes, sino que se llenarán de honestidad y capacidad [...] los García Vigilistas predominan en el partido, constituyendo esto un peligro. ${ }^{29}$

Estas diferencias entre partidos en el momento de las elecciones en Oaxaca revelan la divergencia de fuerzas existentes al interior del estado, principalmente, muestran la complejidad de las instituciones que trataban de aglutinar y llegar al poder.

${ }^{29}$ AGN, DIPys, c. 174, exp. 2, ff. 68-69. 


\section{Candidatos postulados}

Los candidatos postulados para contender en la elección fueron tres personajes importantes de la vida política oaxaqueña: Rubén Morales, apoyado por el Partido Liberal Independiente; el general Onofre Jiménez, apoyado por los partidos Agrarista, Laborista, Demócrata Revolucionario y el Sierra Juárez; José Vasconcelos participó como candidato independiente, contando con el apoyo de un grupo de intelectuales, en su mayor parte de simpatizantes del exgobernador García Vigil relacionados con la rebelión delahuertista.

Rubén Morales estudió en el Colegio Militar de Chapultepec. Más tarde apoyó la candidatura reyista; en 1910 fue vocal del Club Central Reyista. Después se adhirió al movimiento antirreleccionista siendo comisionado para incorporar oficiales del ejército al movimiento revolucionario. Al triunfo de Madero, formó parte de su estado mayor, comisionado para incorporar oficiales al movimiento revolucionario. Participó, posteriormente, en la defensa del gobierno instaurado - después de la rebelión suscitada en el estado de Oaxaca-. Figuró como dirigente del Partido Liberal Independiente, que lo apoyó en la candidatura para gobernador en $1924 .{ }^{30}$

En lo que concierne al general y profesor Onofre Jiménez Ramírez, su participación más notable se aprecia desde el gobierno de Juárez Maza, en 1911, donde formó parte del Batallón Sierra Juárez, como jefe de la $2^{a}$ Compañía. En 1914, junto con otros generales serranos, como Guillermo Meixueiro, contribuyó a la deposición del gobernador Bolaños Cacho. En 1915, se unió al Movimiento de la Soberanía como parte de las Fuerzas Defensoras del Estado. Durante la rebelión de García Vigil, en 1923, participó en la $1^{\text {a }}$ Brigada de División de la Sierra Juárez, ${ }^{31}$ teniendo el curriculum necesario para convertirse en candidato a gobernador y ser apoyado por Obregón.

${ }^{30}$ Arellanes Meixueiro, et al., Diccionario histórico, p. 156.

${ }^{31}$ Arellanes Meixueiro, et al., Diccionario histórico, pp. 120-121. 
Respecto a la figura de José Vasconcelos, se sabe más de su trayectoria tanto intelectual como política. Oriundo de la entidad -como los otros candidatos-, tuvo su formación educativa e intelectual fuera del estado y del país. Sus primeras incursiones en la vida intelectual comenzaron al integrarse al Ateneo de México, liderado por Antonio Caso; más tarde participó junto con Alfonso Reyes, Pedro Henríquez Ureña y otros en la fundación del Ateneo de la Juventud. En 1908 se unió al movimiento maderista, siendo un elemento importante para hacer propaganda en favor de Madero en Oaxaca, en los inicios de la Revolución mexicana. Formó parte del Club Político Antirreleccionista en la ciudad de México, y comenzó a dirigir el periódico Antirreleccionista. ${ }^{32} \mathrm{Si}$ bien Vasconcelos se encontraba fuera del país durante las elecciones marcadas por el movimiento maderista en las que se reeligió Porfirio Díaz, regresó al país participando activamente en el movimiento.

Al producirse el golpe de estado de Victoriano Huerta, Vasconcelos se mantuvo en el exilio en Estados Unidos siendo nombrado por Venustiano Carranza como agente confidencial en Washington. Con el triunfo de las fuerzas constitucionalistas, regresó al país y se le nombró director de la Escuela Nacional Preparatoria, pero tras desavenencias con Carranza, se exilió. Durante el -brevegobierno de la Convención Nacional, Vasconcelos regresó a México para participar como subsecretario de Instrucción Pública y Bellas Artes, sin embargo, entre 1916 y 1919 se mantuvo nuevamente en el exilio, hasta 1920, cuando se alineó con Álvaro Obregón. ${ }^{33}$

Su participación más reconocida fue en el ámbito educativo entre 1920-1924, donde su trayectoria intelectual se consolidó de modo que le valió el reconocimiento nacional e internacional. En 1920, durante el gobierno interino de Adolfo de la Huerta, fue designado rector de la Universidad Nacional, cuya tarea principal consistio en la reorganización

${ }^{32}$ Arellanes Meixueiro, et al., Diccionario histórico, p. 208.

${ }^{33}$ Arellanes Meixueiro, et al., Diccionario histórico, p. 209. 
de la universidad. Al crearse la Secretaría de Educación Pública, en 1921, Vasconcelos fue nombrado secretario y llevó a cabo una vigorosa tarea educativa que comprendió aumento en el número de escuelas, campañas de alfabetización, distribución de libros. En su administración consiguió el mayor monto del presupuesto otorgado a la educación.

No obstante, 27 meses después de ser nombrado secretario de Educación, como consecuencia del asesinato del senador Francisco Field - quien estaba en desacuerdo con los Tratados de Bucareli-,Vasconcelos renunció a su cargo el 28 de enero de 1924. Sin embargo, su renuncia no fue aceptada en un primer momento por Obregón. ${ }^{34}$

Vasconcelos renunció definitivamente a la Secretaría de Educación el 30 de junio de 1924, encaminado a participar en la contienda en Oaxaca. Con las anteriores referencias sobre la trayectoria de los candidatos, se aprecia si los candidatos infringieron o no en lo dispuesto tanto en la Constitución local como en la ley para ser candidatos idóneos.

Dos de las figuras centrales de la contienda electoral infringieron en lo establecido en la Constitución local y leyes vigentes al momento de la elección: el general Jiménez y Vasconcelos. El general Jiménez incumplía lo establecido en el artículo 68 constitucional, inciso VII, ya que en el momento de su candidatura, no debía de encontrarse en el servicio dentro de la milicia. Vasconcelos, renunció definitivamente a la Secretaría de Educación en junio de 1924, por tanto, incumplió con lo establecido en el texto, constitucional porque se separa del cargo el mismo año de la elección, asimismo, violó lo dispuesto en el artículo 68, inciso III.

Sin embargo, se agrega un inconveniente más que llama la atención de la opinión pública: algunas personas que apoyaron la candidatura de Vasconcelos simpatizaron en gran medida con la rebelión de García Vigil. En el "Informe del Agente de Primera

34 Barrón, "Un civil en la busca del poder: la carrera política de José Vasconcelos 1911-1924", p. 16. 
núm. 8...": mencionan algunos nombres de los participantes en la rebelión figurando: "Manuel Chávez, Adalberto Lagunes, Andrés Ruiz, Guillermo Maqueo Castellanos, que fue jefe de los inspectores de Hacienda; José Leyva, Comisario en tiempos de García Vigil; y un señor de apellido Mijangos". ${ }^{35}$ En el informe se menciona el sentir de los partidarios de Vasconcelos señalando que: "el general Onofre Jiménez secundó a la revolución firmando el Plan por medio del cual fue desconocido el Gobierno [...]". ${ }^{36}$ Pese a lo anterior, las faltas a la Constitución y a la ley electoral del estado no fueron impedimento para que el general Jiménez y Vasconcelos fueran partícipes de la elección.

\section{Campañas electorales}

La documentación revisada no detalla, de manera particular, el proceso de campaña de los candidatos Morales y el general Jiménez. En la prensa se menciona la existencia del llamado comité proJiménez para apoyar a su candidato, es decir al general Jiménez, únicos testimonios sobre el tema. No obstante, en relación con la campaña de Vasconcelos existe información que nos acerca a su campaña en Oaxaca. A partir de El Desastre. Tercera Parte de Ulises Criollo, Vasconcelos describe desde que quedó vacante el puesto de gobernador - por la muerte de García Vigil-, el ofrecimiento de la candidatura por parte de Genaro V. Vázquez y la despedida que tuvo con Calles. Respecto a la promoción de su candidatura, señala: "para una campaña política democrática, la prensa es un factor decisivo. De nada sirve ir teniendo éxito, lograr que se reúnan muchedumbres, si no hay nadie que lo diga". ${ }^{37}$ Periódicos como El Universal y Excélsior mencionaron en sus páginas el avance de su candidatura. Otros periódicos, como indica mordazmente Vasconcelos: "El Machete, órgano de los comunistas de la pintura, se puso a mis órdenes, apoyó a mi candidatura con

\footnotetext{
${ }^{35}$ AGN DIPys, c. 174 , exp. 2 f. 70

${ }^{36}$ AGN DIPys, c. 174, exp. 2 f. 70

${ }^{37}$ Vasconcelos, Memorias II, p. 268.
} 
artículos que, por supuesto, nadie leía en Oaxaca. De todos modos, y por de pronto, agradecí el gesto". ${ }^{38}$ Sin embargo, las desavenencias entre Vasconcelos y el grupo que dirigía el periódico El Machete eran evidentes, por lo que estos últimos mencionaban al respecto de su candidatura y participación en la elección de 1924:

No hace falta reconocer interiormente la actuación del Lic. José Vasconcelos como candidato al gobierno de Oaxaca para comprender que ha cometido un error, una falta de tal magnitud grave que caerá fatalmente sobre su personalidad de revolucionario, por una parte, y sobre su prestigio de hombre inteligente por la otra... ${ }^{39}$

A pesar de las críticas recibidas en torno a su candidatura, Vasconcelos contó con el apoyo de los intelectuales, estudiantes y maestros, además de los llamados comités pro Vasconcelos que se formaron en algunas partes del estado. La llegada del candidato a la ciudad de Oaxaca estuvo amenizada por "las campanas de la catedral, música, aplausos y aclamaciones de sus seguidores. No obstante se presenciaran amenazas contra los vasconcelistas en algunas partes del estado". ${ }^{40}$ A partir de sus memorias, Vasconcelos menciona cómo se llevó a cabo su campaña:

Llegaron a insinuar algunos que no era ni necesario que
visitara el estado, porque la campaña podría desarrollarse
sin mi presencia, dirigida por mí desde la capital. Nunca
me ha gustado hacer las cosas a medias. Puesto que había

${ }^{38}$ Vasconcelos, Memorias II, p. 268.

39 "El pleito electoral del Estado de Oaxaca", en El Machete, del 21 al 28 de agosto de 1924. Agradezco al doctor Javier Mac Gregor Gampuzano por haberme señalado esta referencia.

${ }^{40}$ Barrón, "Un civil en la busca del poder: la carrera política de José Vasconcelos 1911-1924", p. 18. 
aceptado la aventura la llevaría adelante y visitaría no sólo la capital, sino también distritos dónde sólo se puede penetrar a lomo de caballo $[\ldots]^{41}$

Posterior a la elección, Vasconcelos amplió su opinión respecto de su campaña y a la de su contrincante, el general Jiménez:

[...] hice en Oaxaca una campaña democrática, activa y concienzuda en todos los distritos y en todas partes fui acogido con entusiasmo por verdaderas multitudes [...] Mi contrincante no se movió de la capital del estado y después se dedicó a aprovechar los constantes amagos que me hizo el gobernador Ibarra con la maquinaria administrativa. ${ }^{42}$

No obstante, las declaraciones de Vasconcelos demuestran - de manera parcial- la existencia de una campaña que dio a conocer su candidatura en el estado; en el caso de los otros candidatos se desconoce la manera en que llevaron a cabo sus campañas electorales.

\section{Las elecciones para gobernador: 3 de agosto de 1924}

\section{De elecciones a chanchullos}

Si bien el 3 de agosto de 1924 se llevaron a cabo elecciones de gobernador y diputados locales, en la historiografía regional este acontecimiento se menciona brevemente, sólo mencionó que el candidato ganador fue el general Jiménez. No obstante, la revisión de fuentes documentales y hemerográficas del periodo revela más información de lo acontecido.

${ }^{41}$ Vasconcelos, Memorias II, pp. 270-271.

42 "La justicia no suplica, demanda: dice el Sr. Lic. Vasconcelos", en El Universal, 16 de agosto de 1924. 
El primer encuentro revela que la jornada electoral en algunos distritos como Huajuapan, Pochutla, Tlacolula, Sola de Vega y Juchitán no presentaron escándalos ni disturbios en las elecciones, y se llevaron con orden y más entusiasmo de lo esperado. Empero, lo que sí existía era la incertidumbre y la especulación sobre el ganador de las elección: Vasconcelos o el general Onofre Jiménez. ${ }^{43}$

Las especulaciones respecto al resultado se hicieron presentes en los diferentes distritos. En lo que respecta a la candidatura del general Jiménez, el comité pro Jiménez se expresó de los resultados en la prensa de la siguiente manera:

[...] el triunfo de nuestro candidato Gral. Onofre Jiménez ha sido abrumador en los siguientes Distritos: Pochutla, Tlacolula, Nochixtlán, San Carlos Yautepec, Villa Alta, Tlacolula, Choápam, Juchitán, Huajuapam, Ocotlán y Juxtlahuaca [...] En todos los pueblos del distrito del centro tuvimos una mayoría abrumadora de votos [...] Continuamente nos están llegando telegramas de diversas poblaciones de la entidad felicitándonos por el triunfo de nuestro candidato. ${ }^{44}$

También declararon los partidarios de Vasconcelos el triunfo de su candidato en diferentes lugares de la entidad:

A cada momento, y por las noticias que se reciben de los distritos, se confirma el triunfo alcanzado por la candidatura civilista del licenciado José Vasconcelos [...] las noticias vienen procedentes de Tehuantepec, Tlaxiaco, Nochixtlán, Teposcolula, Juchitán, Juquila, Salina Cruz, Pochutla, Zimatlán, Etla y Teotitlán del Camino. ${ }^{45}$

\footnotetext{
43 "Las elecciones en los Distritos", en El Informador, 5 de agosto de 1924. 44 "Boletín del Comité Pro Jiménez", en El Informador, 5 de agosto de 1924. 45 "A pesar de atentados y chanchullos la candidatura de Vasconcelos triunfó en Oaxaca", en El Universal, 6 de agosto de 1924.
} 
Las diferentes especulaciones declaradas en la prensa no fueron ajenas a los candidatos, quienes también opinaron sobre su participación y el seguimiento de las elecciones. El general Jiménez opinó:

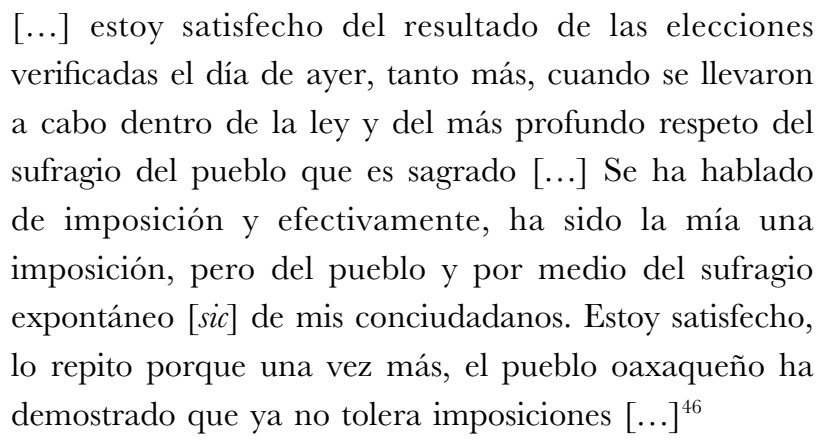

De igual forma, Vasconcelos declaró en la prensa lo siguiente:

Tenemos segura mayoría no sólo en la elección del Ejecutivo sino en la de Diputados. Esto nos garantiza la seguridad. A cada chanchullo responderemos con una victoria para vergüenza política de nuestros enemigos, no obstante la imposición. Mis partidarios están documentándose para exigir responsabilidades por los incalificable fraudes electorales que cometieron en complicidad con las autoridades. ${ }^{47}$

Al término de la jornada electoral, las denuncias y quejas emitidas por los simpatizantes de Vasconcelos, candidatos a la diputación local y miembros del grupo pro Vasconcelos se reflejaron en la prensa,

\footnotetext{
46 "Al margen de las elecciones, jimenistas y vasconcelistas dicen haber triunfado", en El Informador, 5 de agosto de 1924.

47 "A pesar de atentados y chanchullos la candidatura de Vasconcelos triunfó en Oaxaca", en El Universal, 6 de agosto de 1924.
} 
ya que fueron foco de atropellos y abusos por parte de las autoridades locales:

En el distrito del centro los fraudes electorales fueron tan escandalosos como frecuentes. Sobre todo en las municipalidades de San Antonio de la Cal, Santa María Trujano, Azompa, San Jacinto Tutla, San Sebastián Tutla, Jalatlaco, Santa María El Tule, Xochimilco, San Agustín Yaterani, San Andrés Ixtlahuaca, santo Domingo Tomaltepec, San Felipe del Agua, Huayapám, San Bartolo Coyotepec [...] los agentes del gobierno de Ibarra se distinguieron en sus especialidades fraudulentas. La sociedad de aquí ha recibido con risas el cómputo de la votación arrojada en favor del señor Onofre Jiménez, pues los padrones arrojan cifras muy diferentes [...].

En San Felipe del Agua, el presidente Municipal decretó que no se admitirían votos en favor del candidato popular, señor Vasconcelos, y cuando su representante (vasconcelista) trató de levantar la protesta, los regidores, el presidente municipal, los topiles y los alguaciles del pueblo lapidaron al representante de Vasconcelos, quien tuvo que salir huyendo a bordo de un automóvil [...]

En Ocotlán se suplantaron a los presidentes de casillas para hacerlos aparecer como miembros de la Computadora.

En esta capital (ciudad de Oaxaca) los enemigos de Vasconcelos, apoyados por el gobierno, durmieron en los zaguanes destinados a casillas electorales y a temprana hora y a puerta cerrada hicieron elecciones.

En Zimatlán, el escándalo es superlativo. El candidato a diputado fue encarcelado la víspera de las elecciones, habiendo recuperado su libertad con intervención del Juez Federal. Su contrincante, Roberto Calvo Ramírez, empleado del Gobierno y uno de los asaltantes al instituto de Ciencias del Estado se puso al frente de 
cuarenta hombres armados y expulsó a tiros al comité vasconcelista y a sus partidarios $[\ldots]^{48}$

Estas quejas también señalaron la forma de actuar del gobierno de Ibarra y de sus colaboradores en las elecciones:

[...] El Gobierno del Señor Ibarra, por medio de jueces, policías y otros elementos de la maquinaria oficial se ha dedicado a destruir los expedientes electorales y a torcer el voto, por lo que los vasconcelistas se han visto precisados a instalar sus computadoras independientes. Los datos que sobre el particular se han proporcionado añaden que los ibarristas han falseado las cifras que arrojan las votaciones tratando de organizar una legislatura apócrifa, e impidiendo, por medio de la fuerza, que sus adversarios políticos, penetren al palacio $\left[\ldots . . .^{49}\right.$

Las quejas trascendieron en contra de la participación de las autoridades estatales durante la elección, de tal manera que incluso la Federación de Estudiantes de México dirigió un mensaje al general Obregón:

La juventud que siempre ha visto en usted al mandatario probo [refiriéndose a Obregón] le ruega interponer sus valiosos oficios a fin de que no se lleve a cabo un escándalo electoral, en aquella región, y que no se vulneren aquellos principios para la revolución que usted ha defendido lealmente a costa de su tranquilidad y su propia vida. $^{50}$

48 "A pesar de atentados y chanchullos la candidatura de Vasconcelos triunfó en Oaxaca" en El Universal, 6 de agosto de 1924.

49 "Como se prepara el gran chanchullo en Oaxaca", en El Universal, 8 de agosto de 1924.

50 "Piden respeto a la voluntad popular", en El Universal, 10 de agosto de 1924. 
Esta situación de desconfianza en los resultados $-\mathrm{y}$ de disturbios durante las elecciones-, propiciaron la instauración de dos juntas computadoras: una por parte de los simpatizantes de Vasconcelos y otra del general Jiménez. Cada una dio el conteo de los votos obtenidos en la elección no sólo para nombrar al nuevo gobernador, sino también para dar los nombres de los diputados electos que integrarían la XXX Legislatura Estatal. No obstante, las cifras emitidas por cada grupo no reflejaron la veracidad de los resultados. Al respecto, el Agente especial núm. 8 menciona:

\begin{abstract}
Algunas personas del pueblo a quienes les pregunté que quién obtuvo el triunfo para gobernador, dicen que Vasconcelos; pero como les dijera que sabía que Jiménez tenía algún partido, me contestaron: Sí, el Gral. Jiménez tuvo más votos, pero Vasconcelos tiene muchos amigos en México y por eso ganó. ${ }^{51}$
\end{abstract}

El problema generado relacionado con los resultados del candidato electo, originó un interés no sólo a nivel estatal sino nacional. El hecho de que se hablara de imposición por parte del candidato oficial, es decir, el general Jiménez, dio pie a considerar la posibilidad de vivir nuevamente un conflicto que pusiera en jaque la estabilidad política de la entidad.

\title{
Acciones postelectorales
}

Una de las acciones posteriores a la jornada del 3 de agosto de 1924, fue la instauración de dos legislaturas: una apoyando al general Jiménez y otra a Vasconcelos, ya que tanto unos como otros se atribuyeron el triunfo de la elección. La legislatura vasconcelista, como se le denominó

${ }^{51}$ AGN DIPys, c. 174, exp. 2, f. 57. 
en la prensa, se instauró días posteriores a la elección incumpliendo lo designado en la ley, disponía que se debería establecer a partir del 1 de septiembre. Este hecho fue liderado por un grupo de once diputados que se instalaron en colegio electoral, en la casa número 42 de la avenida Independencia de aquella entidad, con el único fin de constituir la legislatura local; entre ellos, los señores Otilio Jiménez, Antonio Castillo, Jesús Álvarez, Emilio Álvarez, Rafael Parada Gay, J. Ramírez, R. Santaella, Ricardo Vázquez y Rafael F. Barroso. ${ }^{52}$ El desconocimiento de la legislatura vasconcelista en las esferas oficiales, propició acusaciones por el delito de rebelión, violación de la soberanía y de rumores de la existencia de parque y municiones.

Aunado a los hechos, el secretario de Gobernación, Enrique Colunga, informó que el gobierno federal mantendría una actitud absolutamente neutral para el caso de Oaxaca, ya que el conflicto suscitado en la entidad era meramente local. Desde que se originó el conflicto, se mencionó, incluso por el propio Vasconcelos, que la resolución estaba en manos del Senado de la República, declarando en la prensa:
Desde que fui a Oaxaca conocía los obstáculos que iba a encontrar, pero no debía rehusarme. Hice un esfuerzo que servirá para demostrarme si es o no posible la democracia relativa, después de catorce años de revolución. ¡Que conteste la Revolución! La justicia no suplica, demanda. A su tiempo hablará el senado. ${ }^{53}$

No obstante el primero de septiembre el tema se discutió en el Senado, dirigido por el denominado Bloque Democrático de la Cámara de Senadores, que al conocer el caso de Oaxaca hicieron

52 "En Oaxaca se teme que se instalen dos legislaturas", en Excélsior, 12 de agosto de 1924 y "Dos legislaturas están funcionando en el edo. de Oaxaca", en El Demócrata, 12 de agosto de 1924.

53 "La justicia no suplica, demanda: dice el Sr. Lic. Vasconcelos", en El Universal, 16 de agosto de 1924. 
varias proposiciones para solucionar el problema. Una solución era designar al senador Eleazar del Valle como gobernador; la segunda era mandar una comisión especializada del Senado para que estudiara el caso Oaxaca y la tercera que se mandara una terna al Ejecutivo para que hiciera la designación de gobernador o se resolvería acorde con la constitución local. ${ }^{54}$

Ante las constantes amenazas de las que siguieron siendo víctimas los vasconcelistas, se rumoró que varios de ellos radicarían en la ciudad de México para salvaguardar su seguridad; empero únicamente una comisión de cuatro diputados se trasladó a la ciudad de México con la intención de entrevistarse con el presidente de la República. ${ }^{55}$ Una de las acciones que llevó a cabo la legislatura vasconcelista, fue instalarse en Rincón Antonio, en la región del Istmo y declarar a Otilio Jiménez Madrigal ${ }^{56}$ como gobernador del estado, para presionar al gobierno federal que interviniera y solucionara el conflicto político.

No obstante, la resolución del conflicto estuvo en manos de la XXX Legislatura reconocida, es decir, la legislatura partidaria del general Jiménez (mencionada en la prensa como legislatura onofrista), instaurada el 16 de septiembre y avalada por el gobierno federal. Con su instauración, se les entregaron los paquetes y documentos electorales que se encontraban depositados en la oficina de correos,

54 "Largo debate provocó el asunto de Oaxaca en el Bloque Democrático", en El Demócrata, 13 de septiembre de 1924.

55 "El conflicto político en Oaxaca se intensifica", en El Universal, 23 de septiembre de 1924.

${ }^{56}$ Otilio Jiménez Madrigal también fue miembro del grupo de serranos que participó activamente en el Movimiento de la soberanía que sucumbió en la entidad entre 1915-1920. Posteriormente, en 1922, junto con Lorenzo Castillo, hizo un llamado contra la política fiscal del gobernador García Vigil en nombre de los serranos, siendo desconocido por Onofre Jiménez. En 1923 combatió la revuelta de García Vigil y, a principios de 1924 fue vocal del Consejo Directivo de las Fuerzas Serranas y jefe de operaciones militares en el estado. Apoyó, junto con Genaro V. Vázquez, la candidatura de José Vasconcelos a la gubernatura del estado. Véase, Arellanes Meixueiro, et al., Diccionario histórico, p. 120. 
provenientes de diferentes partes del estado, para que el grupo de presuntos diputados que señale el gobernador de la entidad funcionar como colegio electoral. ${ }^{57}$

El conflicto derivado por el reconocimiento del general Jiménez o de Vasconcelos como gobernador electo, era señalado en la prensa junto con los casos de otras entidades como Aguascalientes y Durango, ${ }^{58}$ donde se presenció el mismo patrón que en Oaxaca, es decir, dos candidatos postulados, pero, a diferencia de lo sucedido en Oaxaca, en ambos estados se reconoció el triunfo de los candidatos electos. Por ejemplo, el periódico Omega con fecha 25 de septiembre cita que en el diario The Herald, del vecino país del norte, se mencionaba la problemática:

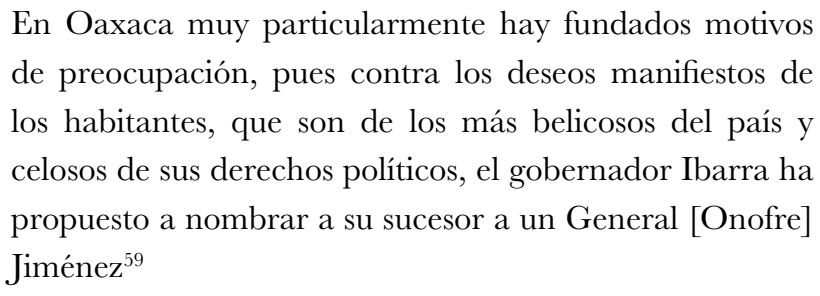

Con la cita anterior se puede pensar que este conflicto causó conmoción no sólo a nivel estatal y nacional, sino también en el extranjero. Tanto la Secretaría de Gobernación como el presidente de la República, no reconocieron como candidato electo a Vasconcelos ni a su legislatura, así que dieron su beneplácito al general Jiménez y la legislatura legalmente instaurada, es decir, los que apoyaron al candidato ganador. Además, la discusión y solución del conflicto no lo llevó a cabo el Senado como se esperaba, sino la legislatura legalmente instaurada fue la encargada de dar por terminada la contienda electoral.

57 "Los paquetes electorales de Oaxaca, fueron entregados", en El Universal, 16 de septiembre de 1924 .

58 "Han desconocido al gobierno del estado de Oaxaca", en Excélsior, 23 de septiembre de 1924 .

59 "La imposición en Oaxaca", en Omega, 25 de septiembre de 1924. 
El 26 de septiembre de 1924 la legislatura local instaurada en el palacio de gobierno $-\mathrm{y}$ reconocida legalmente por el gobierno federal-, decidió la elección en favor del candidato oficial: el general Jiménez. Los resultados de la contienda se hicieron públicos después de la incertidumbre vivida desde la jornada electoral, quedando las cifras de la siguiente manera: general Jiménez 100,072 votos; José Vasconcelos 33,650 votos y Rubén Morales 730 votos. ${ }^{60}$ En la prensa se hizo manifiesto el dictamen hecho por la legislatura:

Ayer a las catorce horas, en sesión solemne que tuvo el congreso local, declaró que por una mayoría de ciento seis mil cuatrocientos once votos, es gobernador constitucional del Estado de Oaxaca para el próximo periodo comprendido del 1 de diciembre al 30 de noviembre de $1928{ }^{61}$

Con respecto de los resultados de elección de gobernador, el agente de primera núm. 8 señala en su informe: "Hasta los mismos partidarios del Gral. Onofre Jiménez y del Gral. Isaac Ibarra, confiesan que hubo imposición $[\ldots]$ ". ${ }^{62}$ De que haya existido imposición de gobernador, no sólo desde el gobierno estatal, sino respaldado desde el gobierno del centro, sugiere en realidad la inestabilidad política dentro del estado y, sobre todo, el papel que jugó el grupo político en el gobierno,

60 "El H. Congreso resolverá quien resultó electo para ocupar en el próximo periodo constitucional la primera magistratura del estado", en El Informador, 26 de septiembre de 1924. Cabe mencionar que la prensa es la fuente que se tiene para conocer los resultados obtenidos en la contienda, empero en "Es Gobernador Constitucional del Estado el general Onofre Jiménez" en El Informador, 27 de septiembre de 1927, se citan los siguientes resultados: Gral. Onofre Jiménez 106,411 votos; José Vasconcelos 35,131 votos; Rubén Morales 750 votos.

61 "Es Gobernador Constitucional del Estado el general Onofre Jiménez", en El Informador, 27 de septiembre de 1924.

${ }^{62}$ AGN DIPys, c. 174, exp. 2, f. 75 , 
es decir, los sonorenses y los serranos. El general Jiménez fue declarado oficialmente como triunfador de las elecciones celebradas el 3 de agosto de 1924, en un escenario donde los chanchullos, atropellos y la imposición se hicieron presentes.

No obstante, en 1925 Oaxaca pasó a ser una de las nueve entidades en las que se cambiaron los titulares del poder ejecutivo del estado. Aprovechando la ausencia del ejecutivo estatal, la legislatura local - con la presencia de la representación oaxaqueña en el Congreso federal--, enjuició la actuación del general Jiménez. A esta acción, con tintes legales y sin detalles cruentos, se le conoció como el Camarazo, que abre a plenitud la época callista en Oaxaca, y de la cual Genaro V. Vázquez fue su más íntegro defensor. ${ }^{63}$ El nombramiento de Vázquez, reflejó el fortalecimiento de personajes civiles que emanaban del poder central, en contraste con los caudillos militares como lo fueron los serranos, cuyo poder no dependía totalmente del centro pues tenían su propia base política.

\section{Consideraciones finales}

Las elecciones del 3 de agosto de 1924 para elegir gobernador en Oaxaca, tuvieron como principal escenario el enfrentamiento entre dos personalidades políticamente activas: el general Jiménez, miembro del grupo serrano apoyado por el centro, versus los deseos de participación de un intelectual como lo fue José Vasconcelos, por lo que se puede entender cómo el tema electoral trascendió no sólo en la entidad, sino que también trastocó la vida nacional.

Si bien es conocida la participación de Vasconcelos en la elección por su obra El Desastre. Tercera parte de Ulises Criollo, en este ensayo se recurrió a la documentación que conserva el Archivo General de la Nación, la cual permitió acercarse a otros participantes como lo fueron Morales y el general Jiménez, además de conocer detalles de

${ }^{63}$ Arellanes, "Un general y un periodo en la vida oaxaqueña", p. 26. 
la jornada electoral como: partidos políticos, campañas electorales, elecciones y acciones postelectorales.

Una peculiaridad de esta elección fue que demostró que la participación de los serranos fue decisiva ante la evidente crisis e inestabilidad política provocada por la muerte de García Vigil, hasta la elección del general Jiménez como gobernador. Al respecto, Garner menciona:

El patrón nacional se reflejó en Oaxaca. Obregón se cuidó de cultivar el apoyo de la nueva generación de caudillos serranos en Oaxaca, que habían surgido en el transcurso de la Revolución para asumir el control político de los destinos de Estado. La intervención de Ibarra y Jiménez después de 1920 resultó decisiva para asegurar la lealtad oaxaqueña al presidente. ${ }^{64}$

A pesar de la participación de candidatos de renombre, como Vasconcelos, sólo el general Jiménez contó con el apoyo para ser elegido gobernador del estado. No obstante, su triunfo estuvo envuelto de atropellos, abusos, chanchullos e incluso se mencionó la imposición, lo que hizo difícil los intentos de estabilidad y de institucionalización acordes con la lógica del centro, por lo que Oaxaca tardaría una brecha más para estar en armonía con lo esperado.

${ }^{64}$ Garner, La Revolución en provincia, p. 241. 


\section{Fuentes y referencias}

\section{Archivos}

Archivo General de la Nación, Fondo Dirección General de Investigaciones Políticas y Sociales, caja 174, expediente 2, $121 \mathrm{ff}$.

\section{Hemerografía}

\section{El Demócrata}

"Dos legislaturas están funcionando en el estado de Oaxaca", 12 de agosto de 1924.

"Largo debate provocó el asunto de Oaxaca en el bloque democrático", 13 de septiembre de 1924.

\section{El Informador}

"Al margen de las elecciones, jimenistas y vasconcelistas dicen haber triunfado", 5 de agosto de 1924.

"Boletín del Comité ProJiménez", 5 de agosto de 1924.

"El H. Congreso resolverá quien resultó electo para ocupar en el próximo periodo constitucional la primera magistratura del estado", 26 de septiembre de 1924.

"Es gobernador constitucional del estado el general Onofre Jiménez", 27 de septiembre de 1927.

"Las elecciones en los Distritos", 5 de agosto de 1924.

\section{El Machete}

"El pleito electoral del estado de Oaxaca", 21-28 de agosto de 1924. 


\section{El Universal}

"A pesar de atentados y chanchullos la candidatura de Vasconcelos triunfó en Oaxaca", 6 de agosto de 1924.

"Cómo se prepara el gran chanchullo en Oaxaca", 8 de agosto de 1924.

"El conflicto político en Oaxaca se intensifica", 23 de septiembre de 1924.

"La justicia no suplica, demanda: dice el Sr. Lic. Vasconcelos", 16 de agosto de 1924.

"Los paquetes electorales de Oaxaca, fueron entregados", 16 de septiembre de 1924.

"Piden respeto a la voluntad popular", 10 de agosto de 1924.

\section{Excélsior}

"En Oaxaca se teme que se instalen dos legislaturas", 12 de agosto de 1924.

"Gran entusiasmo hubo en Oaxaca por las elecciones", 8 de agosto de 1924.

"Han desconocido al gobierno del estado de Oaxaca", 23 de septiembre de 1924.

\section{Omega}

"La imposición en Oaxaca", Omega, 25 de septiembre de 1924.

\section{Bibliografía}

Arellanes Meixueiro, Anselmo, et al., Diccionario histórico de la Revolución en Oaxaca, México, Instituto Nacional de Estudios Históricos sobre las Revoluciones en México-Universidad Autónoma Benito Juárez de Oaxaca, 2000. 
, "Un general y un periodo en la vida oaxaqueña", Oaxaca de Juárez, México, en Cuadernos del sur. Ciencias Sociales, año 4, núm. 4, agosto de 1997.

Barrón, Luis, "Un civil en la busca del poder: la carrera política de José Vasconcelos 1911-1924", en Documentos de trabajo, CIDEDivisión de Historia, núm. 19, 2002.

Chassen-López, Francie, Oaxaca: entre el liberalismo y la Revolución: la perspectiva del sur, 1867-1911, México, Universidad Autónoma Metropolitana-Unidad Iztapalapa-Universidad Autónoma Benito Juárez de Oaxaca, 2010.

Universidad Autónoma Benito Juárez de Oaxaca, 2010. “Constitución Política del Estado libre y Soberano de Oaxaca. 4 de abril de 1922" en Villegas Moreno, Gloria y Miguel Ángel Porrúa Venero (coords.), La estabilidad política y la modernización económica. Un pacto para la nación 1906-1917, México, Miguel Ángel PorrúaLVI Legislatura-Instituto de Investigaciones Legislativas, 1997.

Dalton, Margarita, Breve historia de Oaxaca, México, El Colegio de México-Fideicomiso Historia de las Américas-Fondo de Cultura Económica, 2004.

Garner, Paul, La Revolución en la provincia. Soberanía estatal y caudillismo serrano en Oaxaca, 1920-1920, 2a. ed., México, Fondo de Cultura Económica, 2003.

"Ley para las elecciones de los poderes Legislativo y Ejecutivo del Estado. 13 de julio de 1922” en Martínez Sánchez, Francisco (coord.), Leyes, decretos y reglamentos electorales del estado de Oaxaca, México, Tribunal Estatal Electoral, 2003.

Martínez Vázquez, Víctor Raúl, "Capítulo 5. El régimen de García Vigil", en Chassen, Francie, et al., La Revolución en Oaxaca 19001930, México, IAPO, 1985.

Ruiz Cervantes, Francisco José, La Revolución en Oaxaca: el movimiento de la soberanía, 1915-1920, México, Fondo de Cultura Económica, 1986. 
"La institucionalización de la Revolución (1920-1940)", en Oaxaca. Historia breve, México, Fondo de Cultura Económica-El Colegio de México, 2010.

Sánchez Silva, Carlos, Crisis política y contrarrevolución en Oaxaca (19121915), México, Instituto Nacional de Estudios Históricos de la Revolución Mexicana-Secretaría de Gobernación, Serie Regiones, 1991.

Tamayo, Jorge, Oaxaca en el siglo XX. Apuntes históricos y análisis político (s.p.i.), 1956.

Tobler, Hans Werner, La revolución mexicana: transformación social y cambio político 1876-1940, México, Alianza, 1994.

Vasconcelos, José, Memorias II. El Desastre. El Proconsulado, México, Fondo de Cultura Económica, 1989. 